\title{
Pathogenicity of Diatrypaceae Species in Grapevines in California
}

\author{
F. P. Trouillas and W. D. Gubler, Department of Plant Pathology, University of California, Davis 95616
}

\begin{abstract}
Trouillas, F. P., and Gubler, W. D. 2010. Pathogenicity of Diatrypaceae species in grapevines in California. Plant Dis. 94:867-872.

Diatrypaceous fungi have been isolated from cankered wood of grapevines (Vitis vinifera) in California. However, the pathogenicity of these fungi and their potential to cause diseases in grapevine was unknown. A series of pathogenicity tests were conducted to determine if these fungi were grapevine pathogens. In all experiments, species of the family Diatrypaceae were reisolated from the margins of developing lesions, although frequency of re-isolation and average length of vascular discolorations varied among isolates. Cryptovalsa ampelina, Diatrype stigma, and Eutypa leptoplaca were capable of colonizing dormant canes and causing vascular necrosis. Cryptosphaeria pullmanensis, C. ampelina, D. stigma, Diatrype whitmanensis, and E. leptoplaca infected and caused lesions in green shoots of the new vegetative growth. Diatrype oregonensis and Diatrypella verrucaeformis isolates did not produce lesions that were significantly different from those produced in the control shoots and canes. This suggests that $D$. oregonensis and $D$. verrucaeformis fungi may be saprophytic rather than pathogenic to grapevine.
\end{abstract}

Grapevine canker diseases in California are responsible for severe economic losses to the grapevine (Vitis vinifera L.) industry, estimated at up to US\$260 million per annum (15). Among them, Eutypa dieback, caused by Eutypa lata (Pers.:Fr.) Tul. \& C. Tul. (Syn.: E. armeniacae Hansf. \& Carter) (Diatrypaceae), constitutes one of the most important canker diseases in California, causing death of arms, cordons, and eventually entire grapevines (9). Several species of fungi belonging to the family Botryosphaeriaceae also have been isolated from grapevine cankers in California, and their pathogenicity has been recently documented (20,21). Furthermore, 11 species of the family Diatrypaceae in addition to E. lata have been reported from diseased wood of grapevines in California (18). The occurrence of diatrypaceous fungi isolated from the margins of active cankers in grapevine in California suggested their participation in causing canker diseases. However, few studies have been conducted to understand their biology and status as canker pathogens of grapevine. Eutypa leptoplaca (Mont.) Rappaz occurs in grapevine in California and is pathogenic to this host (17). Additional diatrypaceous species have been shown to cause disease in cultivated grapevines around the

Corresponding author: Walter D. Gubler E-mail: wdgubler@ucdavis.edu

* The $\boldsymbol{e}$-Xtra logo stands for "electronic extra" and indicates that Figures 5 and 6 appear in color online.

Accepted for publication 5 February 2010.

doi:10.1094/PDIS-94-7-0867

(C) 2010 The American Phytopathological Society world. Cryptovalsa ampelina (Nitschke) Fuckel was isolated from grapevine canes in South Africa and Australia, and its pathogenicity to grapevine was established (10). C. ampelina also was reported from $V$. vinifera in northeastern Spain, and its pathogenicity to grapevine was confirmed, although the authors suggested moderate virulence for this fungus (8). Recently, Úrbez-Torres et al. (19) proved the pathogenicity to grapevine of the diatrypaceous fungi Eutypella vitis (Schwein.:Fr.) Ellis \& Everh. (Syn.: E. aequilinearis (Schwein.: Fr.) Starb.) and Diatrypella sp., although the authors suggested a low virulence for these fungi.

Despite the abundance of Diatrypaceae species in grapevine cankers in California, the status of these fungi as pathogens remained unknown. The objective of the present study was to determine the pathogenicity in grapevine of the most common diatrypaceous species found in California.

\section{MATERIALS AND METHODS}

Twenty-eight isolates of diatrypaceous fungi were used in this study. Isolates were collected from diseased grapevine wood and native tree species in six California counties (Table 1). Fungal isolates were obtained from ascospores as well as from hyphae in infected grapevine wood (18). Pure cultures were obtained by isolation of hyphal tips. Species were identified morphologically and separated using phylogenetic analyses of the complete sequence of the internal transcribed spacer (ITS) of the rDNA and $\beta$-tubulin gene (18).

Three pathogenicity tests were conducted in commercial vineyards on $\mathrm{V}$. vinifera grapevines. Inoculations were done in green shoots as well as in dormant shoots of mature grapevines using an asco- spore suspension or mycelium of the various diatrypaceous fungi.

Pruning wound inoculation. An initial pathogenicity test was conducted using 10year-old Merlot grapevines in a vineyard in Napa County, CA. In this trial, one 1-yearold cane per grapevine and 10 grapevines per fungal inoculation were used. Fresh pruning wounds were made above the node at the tip of approximately eight buds on 1-year-old dormant shoots in December 2001. Shoots were inoculated following pruning by applying $10 \mu \mathrm{l}$ of an ascospore suspension (200 ascospores $\mu^{-1}$ ) directly onto the surface of fresh pruning wounds. Ascospores were obtained from perithecia that were sliced opened with a blade and wetted with sterile water (18). Treatments included inoculations of Eutypa leptoplaca isolates DRSN200 and DCA400, E. lata isolates DCA700 and DCA200, Cryptovalsa ampelina isolates DHB600 and DCA1100, Diatrype oregonensis (Wehm.) Rappaz isolates DHB200 and DCA600, and Diatrypella verrucaeformis (Ehrh.:Fr.) Nitschke isolate DHB500.

In the absence of perithecia, isolate DCHR5 of Diatrype stigma (Hoffm.:Fr.) Fr. was inoculated onto shoots with mycelium placed on the surface of fresh pruning wounds. Mycelium was obtained by scraping the margin of a 10-day-old colony cultured on potato dextrose agar (PDA) amended with $100 \mathrm{ppm}$ tetracycline (PDAtet), grinding the scrapings using an Eppendorf tube and pestle, and suspending in sterile water. There was no control inoculation in this experiment.

Twelve months after inoculation, the percentage of recovery (positive infection) was estimated for each isolate after culturing of necrotic tissues on PDA-tet. Tissue samples for isolations were taken from along the length of vascular streaking to estimate the extent of colonization by each of the tested isolates. Results are represented as the average distance of recovery from the inoculation point and along the necrotic lesions. Fragments of necrotic tissue were cultured on PDA-tet, and characteristic mycelial growths of the various Diatrypaceae species were transferred to fresh PDA-tet petri dishes in an attempt to obtain clean cultures for identification using colony morphology and growth rate.

Dormant cane inoculation. Another pathogenicity test was performed on mature Shiraz and Ruby Cabernet grapevines at the Kearney Agricultural Center of the University of California in Parlier. Inoculations were made in February 2005 in dormant canes using eight isolates represent- 
ing five species of Diatrypaceae (E. lata isolates DCA900 and DCA700, E. leptoplaca isolate DCA500, Diatrype stigma isolate DCASH200, C. ampelina isolates DRO101 and DHB600, and Diatrypella verrucaeformis isolates DHB500 and DCH500). Ten shoots per fungal isolate were inoculated. Inoculations were made by wounding canes at internodes 3 or 4 using a knife. An agar plug with fresh mycelium obtained from the margin of a 10-day-old colony was placed on the surface of each wound. Control shoots were inoculated with noncolonized agar plugs. Inoculated wounds were covered with Vaseline and wrapped with Parafilm. After 2 years, shoots were collected from the field for laboratory examination of canker formation, extent of vascular discoloration, and recovery of fungal isolates.

Green shoot inoculation. Ten-year-old Chardonnay grapevines planted at the viticulture experimental station of the University of California, Davis were used in this pathogenicity test. Green shoots were inoculated on 12 June 2006 using 15 isolates representing eight species of Diatrypaceae (Eutypa lata isolates UCD746St and UCD782St, E. leptoplaca isolates DHB800 and DCA300, Diatrype stigma isolates DCASH200 and DBEY600, D. oregonensis isolates DVIT200 and DBEY300, Diatrype whitmanensis J.D. Rogers \& Glawe isolates DDES300 and DCA1300, Cryptosphaeria pullmanensis Glawe isolates HBPF24 and UCD730SJ, Cryptovalsa ampelina isolates UCD779St and DCA1100, and Diatrypella sp. isolate UCD1268So). Inoculations were made at internodes 4 to 6 using a $4-\mathrm{mm}$ cork borer to remove bark and placing an agar plug from the growing margin of an 8-day-old colony directly on the fresh wound. In this experiment, six shoots per fungal isolate were inoculated. Control shoots were inoculated with noncolonized agar plugs. Inoculated wounds were covered with Vaseline and wrapped with Parafilm. Shoots were collected after 10 weeks for laboratory examination. Fungi obtained from re-isolation were identified based on colony size, shape, color, and growth rate.

Statistical analyses. Statistical analyses were performed using analysis of variance (ANOVA) in SAS (Version 9.1.3; SAS Institute, Cary, NC). Log transformations were performed to reduce heteroscedasticity. Dunnett's $t$ test was used to assess significant differences in the extent of vascular discoloration between the control

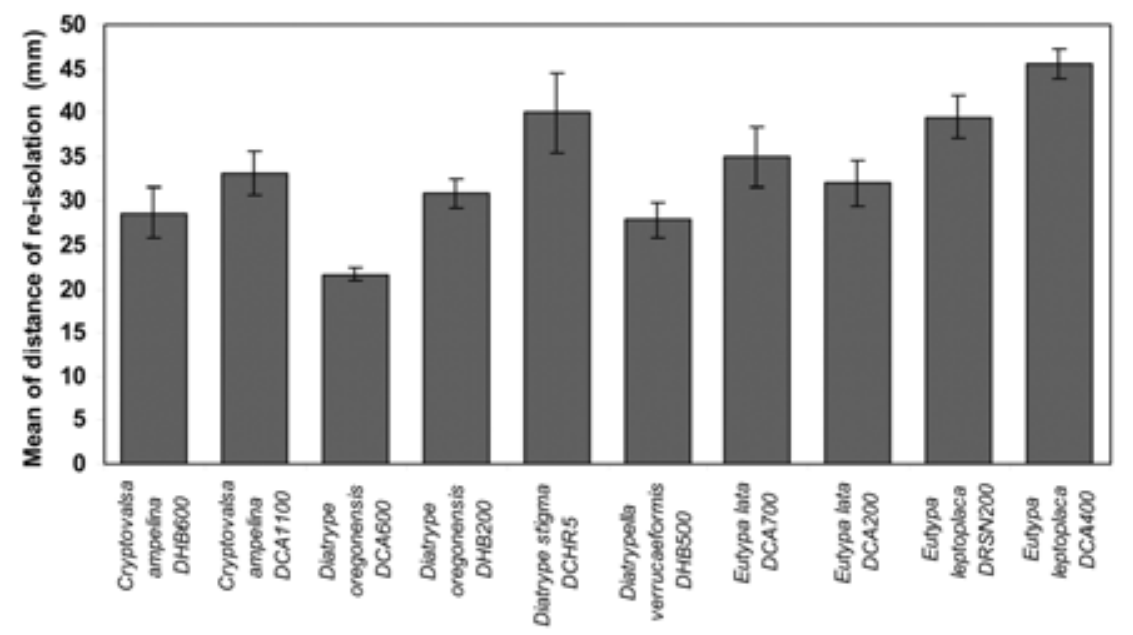

Diatrypaceae isolates

Fig. 1. Mean of distance of re-isolation from pruning wound 1 year after inoculation of various diatrypaceous isolates in Merlot grapevine shoots $(P<0.2153)$. Inoculations were made in the field using $200-\mu \mathrm{l}^{-1}$ ascospore suspensions. Isolate DCHR5 was mycelial inoculated. Bars represent standard error of the mean.

Table 1. Origin and source of Diatrypaceae isolates used in pathogenicity studies

\begin{tabular}{|c|c|c|c|c|c|}
\hline Species & Collection no. & Host & County & $\begin{array}{l}\text { ATCC } \\
\text { accession no. }\end{array}$ & $\begin{array}{l}\text { ITS }{ }^{\text {a }} \text { rDNA GenBank } \\
\text { accession no. }\end{array}$ \\
\hline Cryptosphaeria pullmanensis & UCD730SJ & Vitis vinifera & San Joaquín & MYA-4416 & GQ293929 \\
\hline C. pullmanensis & HBPF24 & Populus fremontii & Sonoma & MYA-4414 & GQ293931 \\
\hline Cryptovalsa ampelina & DCA1100 & V. vinifera & Napa & MYA-4399 & GQ293903 \\
\hline C. ampelina & UCD779St & $V$. vinifera & Stanislaus & MYA-4400 & GQ293907 \\
\hline C. ampelina & DRO101 & Prunus armeniaca & Stanislaus & & GQ293902 \\
\hline C. ampelina & DHB600 & $V$. vinifera & Sonoma & & \\
\hline Diatrype oregonensis & DBEY300 & Umbellularia californica & Yolo & & \\
\hline D. oregonensis & DHB200 & $V$. vinifera & Sonoma & MYA-4412 & GQ293937 \\
\hline D. oregonensis & DVIT200 & Vitis californica & Yolo & & GQ293943 \\
\hline D. oregonensis & DCA600 & V. vinifera & Napa & & GQ293942 \\
\hline Diatrype stigma & DBEY600 & Quercus sp. & Napa & & \\
\hline D. stigma & DCHR5 & $V$. vinifera & Yolo & & GQ293945 \\
\hline D. stigma & DCASH200 & Quercus sp. & Yolo & MYA-4419 & GQ293947 \\
\hline Diatrype whitmanensis & DCA1300 & V. vinifera & Napa & & \\
\hline D. whitmanensis & DDES300 & Acer macrophyllum & El Dorado & & \\
\hline Diatrypella verrucaeformis & DHB500 & V. vinifera & Sonoma & MYA-4407 & GQ293925 \\
\hline D. verrucaeformis & DCH500 & Quercus sp. & Napa & MYA-4408 & GQ293926 \\
\hline Diatrypella sp. & UCD1268So & $V$. vinifera & Sonoma & MYA-4403 & GQ293924 \\
\hline Eutypa lata & UCD746St & $V$. vinifera & Stanislaus & & \\
\hline E. lata & UCD782St & $V$. vinifera & Stanislaus & & \\
\hline E. lata & DCA200 & A. macrophyllum & Napa & & \\
\hline E. lata & DCA700 & $V$. vinifera & Napa & & \\
\hline E. lata & DCA900 & $V$. vinifera & Napa & & GQ293948 \\
\hline Eutypa leptoplaca & DHB800 & $V$. vinifera & Sonoma & MYA-3379 & AY684231 \\
\hline E. leptoplaca & DRSN200 & V. vinifera & Sonoma & & AY684237 \\
\hline E. leptoplaca & DCA300 & A. macrophyllum & Napa & MYA-3382 & AY684229 \\
\hline E. leptoplaca & DCA400 & A. macrophyllum & Napa & & \\
\hline E. leptoplaca & DCA500 & U. californica & Napa & MYA-3381 & AY684230 \\
\hline
\end{tabular}

a Internal transcribed spacer. 
group mean and the remaining treatment group means.

\section{RESULTS}

Pruning wound inoculation. Colonization of dormant grapevine shoot wounds using ascospores was successful for all isolates tested. Fungi obtained from reisolation were the same as the previously inoculated fungal isolates based on colony morphology and growth rate. Percent recovery was lowest for Diatrype oregonensis isolate DCA600 (30\%), C. ampelina isolate DHB600 (40\%), and D. stigma isolate DCHR5 (40\%). Highest percent recovery was obtained for E. leptoplaca isolates DRSN200 and DCA400 (100 and $90 \%$, respectively), E. lata isolates DCA200 and DCA700 (100 and 90\%, respectively), and $C$. ampelina isolate DCA1100 (80\%). D. oregonensis isolate DHB200 and Diatrypella verrucaeformis isolate DHB500 were recovered from 60 and $70 \%$ of the inoculated sites, respectively. The average distance of growth in wood was not significantly different (at $\alpha=$ $0.05)$ among the treatments $(P<0.2153)$ and varied between $21.7 \mathrm{~mm}(D$. oregonensis isolate DCA600) and $45.5 \mathrm{~mm}$ (E. leptoplaca isolate DCA400) (Fig. 1).

Dormant cane inoculation. Results of the 2-year pathogenicity tests are summarized in Figures 2 and 3. In both cultivars, fungal isolates were re-isolated from lesions and identified as being identical to the inoculated isolates. In Shiraz grapevines, best percentages of recovery were found also for E. leptoplaca $(60 \%), D$. verrucaeformis ( $80 \%$ ), and E. lata (70 and $90 \%$ ) isolates. Percentage of fungal recovery were lowest for D. stigma $(20 \%)$ and C. ampelina (40\%). Length of vascular discolorations averaged approximately 39 $\mathrm{mm}$ for $D$. verrucaeformis isolates DCH500 and DHB500, $50 \mathrm{~mm}$ for E. leptoplaca isolate DCA500 and D. stigma isolate DCASH200, 50.7 and $59.4 \mathrm{~mm}$ for E. lata isolates DCA700 and DCA900, respectively, and 47 and $55 \mathrm{~mm}$ for $C$. ampelina isolates DHB600 and DRO101, respectively (Fig. 2). Vascular discoloration in the control vines averaged 28.3 mm. ANOVA of the transformed data set showed significant differences among fungal treatment $(P=0.0129)$. The Dunnett's $t$ test showed significant differences between treatments with E. lata (isolates DCA700 and DCA900) and $C$. ampelina isolate DRO101 from control vines (Fig. 2).

In Ruby Cabernet grapevines, percent fungal recovery from 2-year-old inoculations was highest for $D$. verrucaeformis, $E$. lata, and E. leptoplaca, which ranged between 80 and $100 \%$. Percent fungal recovery for D. stigma and C. ampelina isolate DRO101 was $30 \%$, whereas $C$. ampelina isolate DHB600 was recovered in only $10 \%$ of the previously inoculated canes. Extent of vascular discoloration averaged $58.3 \mathrm{~mm}$ for C. ampelina isolate DRO101,
$55.5 \mathrm{~mm}$ for $E$. leptoplaca isolate DCA500, 50 and $52.5 \mathrm{~mm}$ for E. lata isolates DCA900 and DCA700, $50 \mathrm{~mm}$ for $D$. stigma isolate DCASH200, approximately $36 \mathrm{~mm}$ for $D$. verrucaeformis isolates DCH500 and DHB500, and $33.3 \mathrm{~cm}$ for the agar-only inoculated control (Fig. 3). ANOVA of the transformed data set showed highly significant differences (at $\alpha$ $=0.05)$ among the treatments $(P<$ 0.0004). The Dunnett's $t$ test showed significant differences between treatments with E. lata isolate DCA700, E. leptoplaca isolate DCA500, C. ampelina isolate DRO101, and D. stigma isolate DCASH200 from control vines (Fig. 3).

Green shoot inoculation. All fungal isolates were re-isolated from the margins

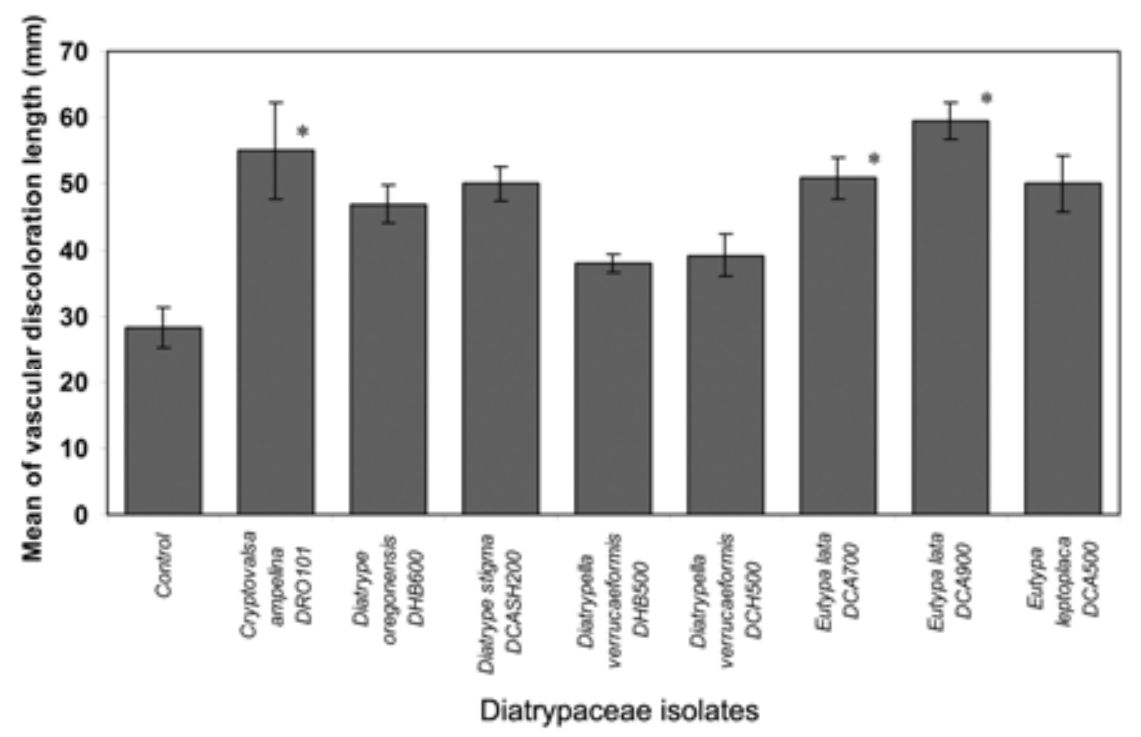

Fig. 2. Mean of vascular discoloration length 2 years after inoculation of various diatrypaceous isolates in Shiraz grapevine shoots inoculated in the field using $200-\mu \mathrm{l}^{-1}$ ascospore suspensions. * Average length of vascular discolorations was significantly different from the agar-only inoculated control according to Dunnett's $t$ test $(P=0.0129)$. Bars represent standard error of the mean.

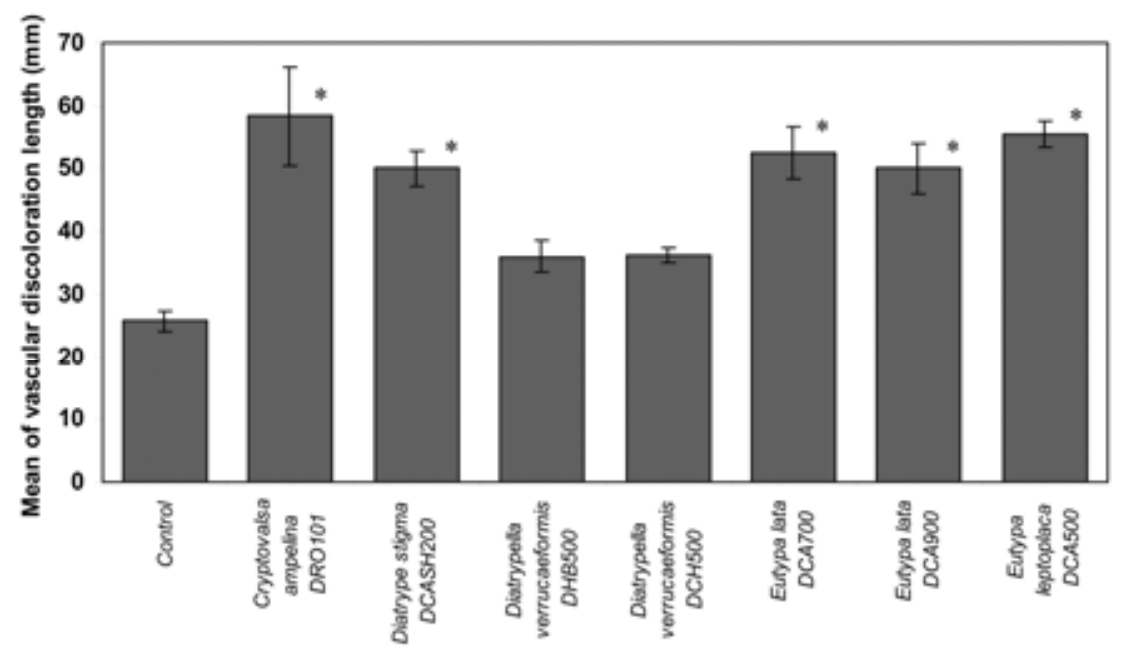

Diatrypaceae isolates

Fig. 3. Mean of vascular discoloration length 2 years after inoculation of various diatrypaceous isolates in Ruby Cabernet grapevine shoots inoculated in the field using $200-\mu 1^{-1}$ ascospore suspensions. * Average length of vascular discolorations was significantly different from the agar-only inoculated control according to Dunnett's $t$ test $(P<0.0004)$. Bars represent standard error of the mean. 
from those measured in the non-inoculated control $(8.6 \mathrm{~mm})$ according to Dunnett's $t$ test (Fig. 4).

\section{DISCUSSION}

Grapevine canker diseases in California have long been attributed mostly to the fungus $E$. lata $(9,21)$. However, other fungal species, particularly in the Botryosphaeriaceae family, have recently been associated with these diseases and shown to constitute the main fungi found in cankers in many regions in California $(20,21)$. Additional studies in California have revealed a great diversity of diatrypaceous fungi associated with grapevine canker diseases $(14,18)$. Recently, E. leptoplaca was isolated from diseased grapevines in California and its pathogenicity was proven (17).

Identification of E. lata has traditionally been conducted based on culture characteristics in agar medium and following isolation of necrotic tissues (1). The majority of fungi in the Diatrypaceae grow as white colonies in culture on PDA-tet resembling E. lata (Fig. 6), which suggests they may have been misidentified and overlooked in previous studies (18). To date, we have reported 11 species of Diatrypaceae from the wood of diseased grapevine in California (18). Fungi in the family Diatrypaceae have typically been isolated from necrotic tissue in shoots, at the margins of wedge shaped cankers in cordons and trunks, cankers in spurs, or as fruiting bodies on the surface of decorticated wood or bark of grapevines (18). The occurrence of these fungi on cultivated grapevines has raised questions regarding their role in vineyard ecosystems and the possibility that they may participate in the overall dieback syndrome of grapevine. However, no information has been available regarding the pathogenicity of these fungi in grapevine.

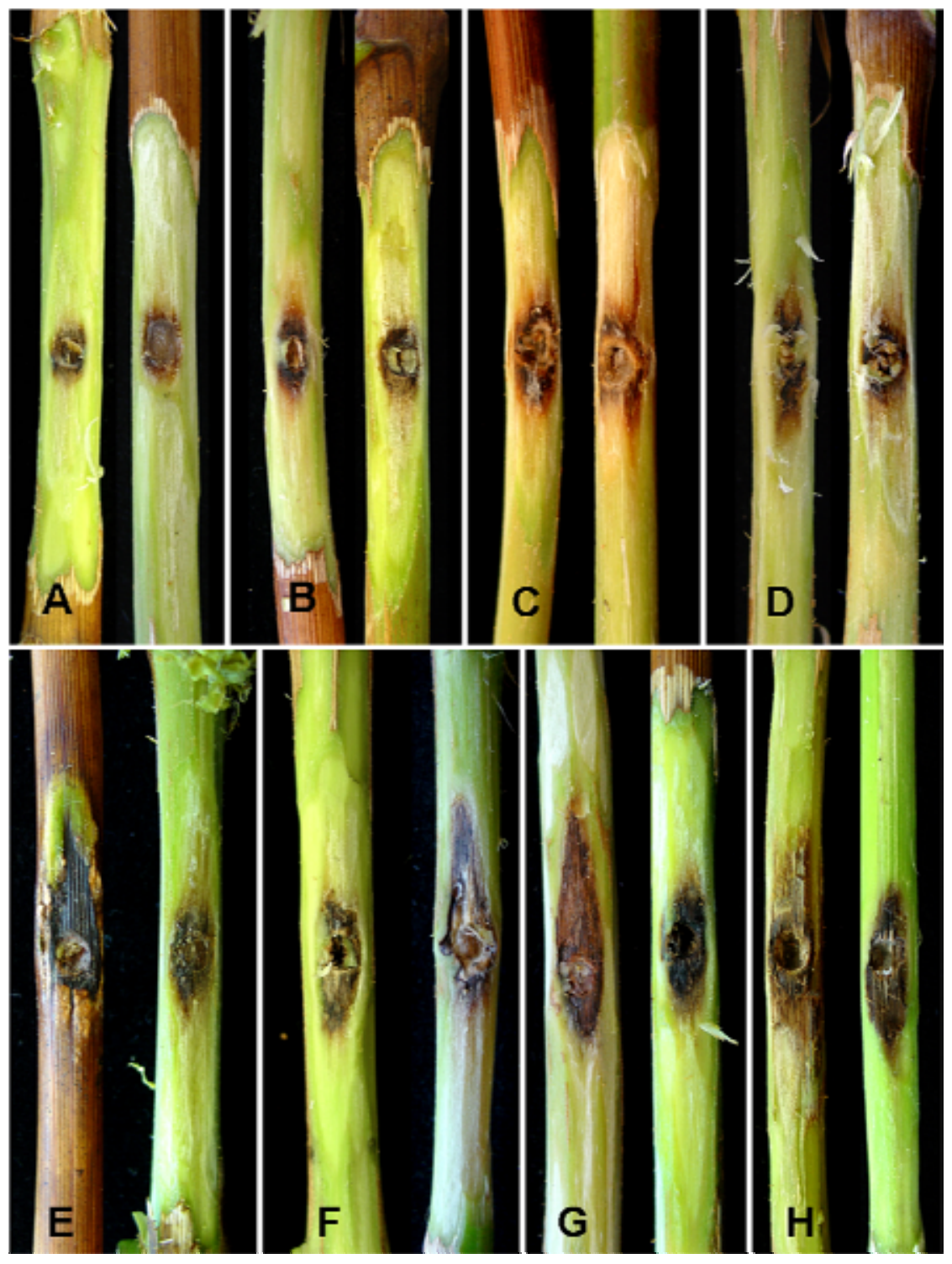

Fig. 5. Lesions caused by Diatrypaceae species in Chardonnay 2.5 months after inoculation in green shoots. A, Control. B, Diatrype oregonensis. C, Diatrypella sp. D, Cryptovalsa ampelina. E, Eutypa leptoplaca. F, Cryptosphaeria pullmanensis. G, Diatrype stigma. $\mathbf{H}$, Eutypa lata.

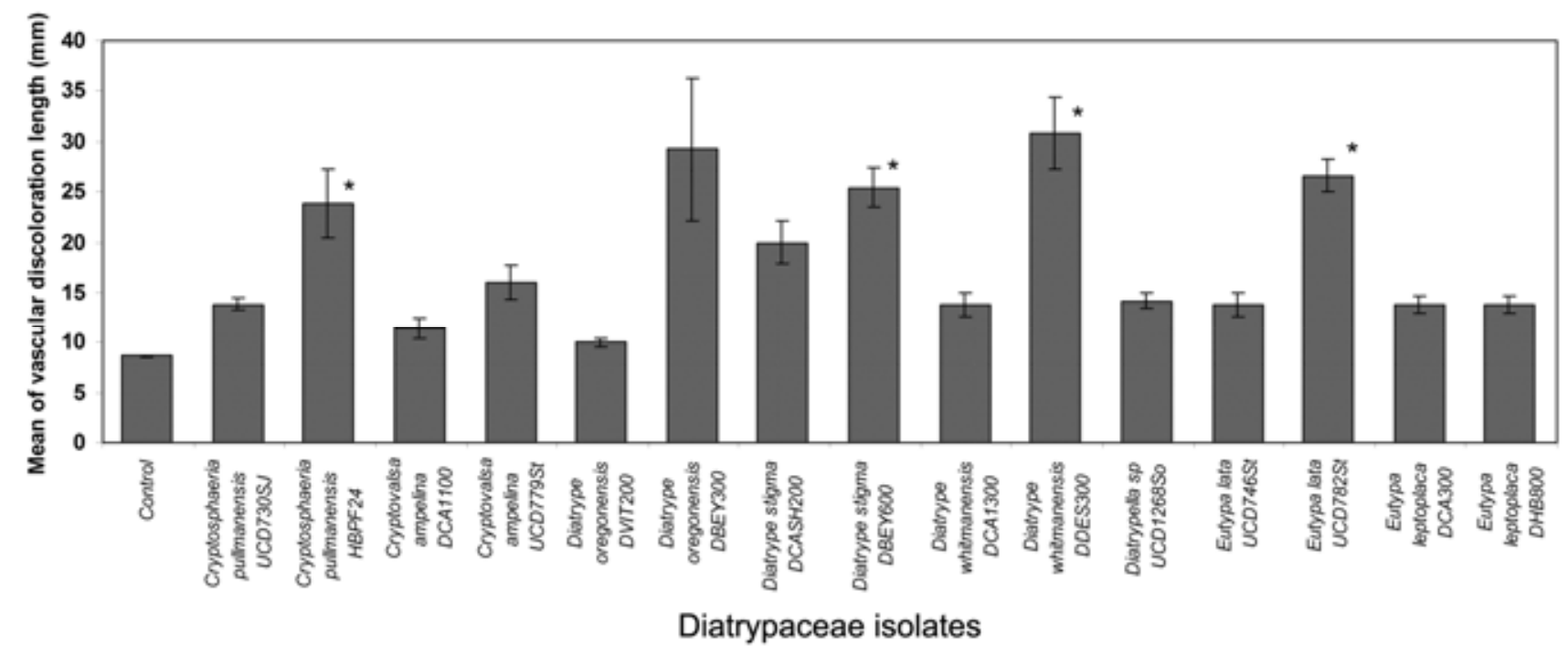

Fig. 4. Mean of vascular discoloration length 2.5 months after inoculation of various diatrypaceous isolates in Chardonnay grapevine green shoots inoculated in the field using mycelium plugs. * Average length of vascular discolorations was significantly different from the agar-only inoculated control according to Dunnett's $t$ test $(P=0.0224)$. Bars represent standard error of the mean. 
In this study, we performed pathogenicity experiments on $V$. vinifera grapevines using species of Diatrypaceae found in California vineyards. Results showed that all species tested were capable of colonizing grapevine wood. In each test, all isolates were re-isolated after a few months to 2 years following inoculations of wounded vegetative or dormant grapevine canes. Isolates of $C$. ampelina, D. oregonensis, $D$. verrucaeformis, and E. leptoplaca colonized dormant grapevine shoots directly after applying ascospore suspension onto the surface of fresh pruning wounds. Isolates of $C$. ampelina, D. stigma, and $E$. leptoplaca were the most virulent in mature wood based on the length of vascular necrosis in the wood and percentage of fungal re-isolation. Isolates of C. pullmanensis, C. ampelina, D. stigma, and D. whitmanensis showed the most virulence in green shoots. They produced lesions and vascular discolorations similar to those produced by E. lata. D. oregonensis and $D$. verrucaeformis produced vascular discolorations not significantly larger than those produced in the control shoots, suggesting they are not pathogenic.

Results of the pathogenicity of C. ampelina agreed with those from previous studies $(8,10)$, although some authors have suggested moderate virulence for this fungus based on the low percentage of fungal recovery (8). Similarly, we observed great variability in the re-isolation and average necrosis length for isolates of the same species, indicating there is an intra-specific variation in virulence. Future experiments will be needed to include more isolates of each Diatrypaceae species to fully assess species aggressiveness on grapevine.

Only a few cankers were observed in our experiments, and the ability of Diatrypaceae to cause perennial cankers similar to those of Eutypa dieback remained uncertain. Extended incubation periods will be necessary in future experiments to better characterize disease expression and aggressiveness of these fungi.

Little is known about the biodegradation potential and wood decay processes used by Diatrypaceae. Pildain et al. (12) found high incidence of cellulase and ligninase within members of the Diatrypaceae family and suggested they are physiologically capable of producing wood decay. Rogers (13) argued that the widespread capacity of Xylariaceae (a sister group of the Diatrypaceae) to destroy lignocellulosic substrates and to degrade tissue would lead to the conclusion that the general lifestyle of these fungi is that of a facultative parasite or facultative saprophyte. Similar concepts may also apply to Diatrypaceae fungi parasitizing healthy or decaying grapevine wood. Species such as $D$. oregonensis and Diatrypella species occurring in the area of canker but showing low virulence to grapevine could be saprophytic.
Surveys for perithecia of Diatrypaceae in northern California vineyards showed the prevalence of E. lata and C. ampelina, which appear fully capable of completing their life cycle on the grapevine host (18). Alternatively, perithecia of E. leptoplaca, $D$. oregonensis, D. whitmanensis, and $D$. verrucaeformis on grapevine were rarely observed $(17,18)$. No perithecia of $D$. stigma have yet been found on grapevine. In contrast, most of these diatrypaceous fungi occur commonly in nature, which suggests spread of these fungi from natural ecosystems into vineyards. Grapevine infections by Diatrypaceae generally occurred sporadically in vineyards surrounded by natural forests, riparian areas, or ornamental plantings where inocula of these fungi are present.

The role of diatrypaceous fungi in nature is not clear, and most species have been regarded as saprobes (3). However, several species in the Diatrypaceae have been shown to cause disease in forest trees. Cryptosphaeria lignyota (Fr.) Auersw. (Syn.: C. populina (Pers.) Sacc.) is a major pathogen of Populus spp. in the western United States $(5,6)$. Eutypella canker caused by Eutypella parasitica R.W Davidson \& R.C. Lorenz is a severe disease of sugar maple (Acer saccharum Marshall) in the northern United States (2). Eutypa spinosa (Pers.:Fr.) Tul. \& C. Tul. was associated with elongated bark lesions (strip-cankers) in European beech (Fagus sylvatica L.) in the United Kingdom (4). The pathogenicity of Diatrype cf. stigma on Quercus suber has been reported in northeastern Spain (7). The authors reported that this fungus could cause stem cankers and vascular necroses. D. stigma as well as E. leptoplaca were isolated from

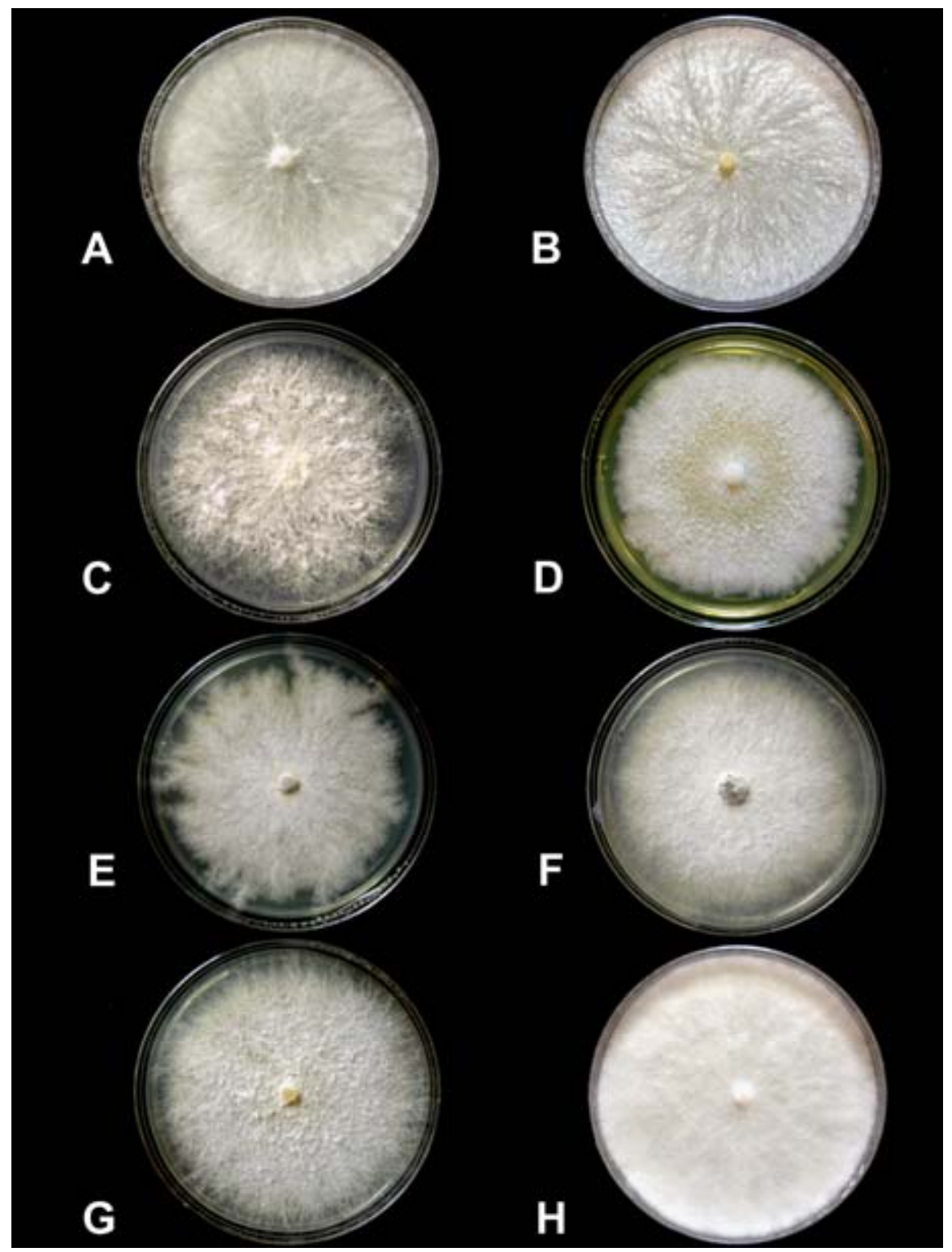

Fig. 6. Fungal colonies of various Diatrypaceae species after 21 days on dishes of potato dextrose agar amended with $100 \mathrm{ppm}$ tetracycline incubated at ambient laboratory light and temperature conditions. A, Cryptovalsa ampelina. $\mathbf{B}$, Diatrype oregonensis. C, Diatrype stigma. D, Diatrype whitmanensis. E, Diatrypella sp. F, Eutypa lata. G, Eutypa leptoplaca. H, Eutypella sp. 
cankers in California bay laurel (Umbellularia californica) (18). D. whitmanensis was isolated from cankers of California buckeye (Aesculus californica) (18). All these observations suggest that some of these fungi could likely be pathogenic to their host in natural environments.

Little is known about environmental influences on the pathogenicity of Diatrypaceae and on the expression of the disease they may cause. Recently, Sosnowski et al. (16) reported that the incidence and severity of foliar symptoms of Eutypa dieback vary from year to year and suggested that this variation is more likely to be caused by climatic factors. Similarly, environmental factors could likely influence symptom expression and disease severity caused by Diatrypaceae. Future experiments could explore the effect of water stress on canker and disease development by Diatrypaceae.

Variation in symptom expression in vineyards affected with Eutypa dieback could be partly explained by the differences in the composition and functioning of the fungal community (11). Diatrypaceae are widely represented in the overall fungal community of grapevine, and their interaction and competition with major grapevine pathogens such as E. lata and the Botryosphaeriaceae should be investigated.

Our experiments have proved that several diatrypaceous species can colonize grapevine and cause vascular streaking similar to that of E. lata. The ability of these fungi to compete with E. lata and Botryosphaeriaceae also is uncertain, and more work needs to be done to understand the significance of these fungi in the overall complex of grapevine canker diseases. Diatrypaceous fungi occur commonly on many woody plants worldwide, and their occurrence in other grape growing regions around the world should be investigated. Also, we anticipate that more species will be shown to be pathogenic to other cultivated or native host plants as more data become available in pathogenicity and identity studies.

\section{ACKNOWLEDGMENTS}

We thank the American Vineyard Foundation and the Viticulture Consortium West for financial support.

\section{LITERATURE CITED}

1. Carter, M. V. 1991. The status of Eutypa lata as a pathogen. Monogr. Phytopathol. Pap. No. 32. Commonwealth Agricultural Bureau, International Mycological Institute, Wallingford, Oxon, UK.

2. Davidson, R. W., and Lorenz, R. C. 1938. Species of Eutypella and Schizoxylon associated with cankers of maple. Phytopathology 28:733-745.

3. Glawe, D. A., and Rogers, J. D. 1984. Diatrypaceae in the Pacific Northwest. Mycotaxon 20:401-460.

4. Hendry, S. J., Lonsdale, D., and Boddy, L. 1998. Strip-cankering of beech (Fagus sylvatica): Pathology and distribution of symptomatic trees. New Phytol. 140:549-565.

5. Hinds, T. E. 1981. Cryptosphaeria canker and Libertella decay of aspen. Phytopathology 71:1137-1145.

6. Hinds, T. E., and Laurent, T. H. 1978. Common aspen diseases found in Alaska. Plant Dis. Rep. 62:972-975.

7. Luque, J., Parladé, J., and Pera, J. 2000. Pathogenicity of fungi isolated from Quercus suber in Catalonia (NE Spain). For. Pathol. 30:247-263.

8. Luque, J., Sierra, D., Torres, E., and Garcia, F. 2006. Cryptovalsa ampelina on grapevines in N.E. Spain: Identification and pathogenicity. Phytopathol. Mediterr. 45:S101-S109.

9. Moller, W. J., and Kasimatis, A. N. 1978. Dieback of grapevine caused by Eutypa armeniacae. Plant Dis. Rep. 62:254-258.

10. Mostert, L., Halleen, F., Creaser, M. L., and Crous, P. W. 2004. Cryptovalsa ampelina, a forgotten shoot and cane pathogen of grapevines. Australas. Plant Pathol. 33:295-299.

11. Péros, J. P., Jamaux-Despréaux, I., Berger, G., and Gerba, D. 1999. The potential importance of the diversity in Eutypa lata and cocolonising fungi in explaining variation in development of grapevine dieback. Mycol. Res. 103:1385-1390.

12. Pildain, M. B., Novas, M. V., and Carmarán, C. C. 2005. Evaluation of anamorphic state, wood decay and production of lignin-modifying enzymes for diatrypaceous fungi from Argentina. J. Agric. Technol. 1:81-96.

13. Rogers, J. D. 2000. Thoughts and musings on tropical Xylariaceae. Mycol. Res. 104:14121420.

14. Rolshausen, P. E., Mahoney, N. E., Molyneux, R. J., and Gubler, W. D.2006. A reassessment of the species concept in Eutypa lata, the causal agent of Eutypa dieback of grapevine. Phytopathology 96:369-377.

15. Siebert, J. B. 2001. Eutypa: The economic toll on vineyards. Wines and Vines, April 2001 Issue: $50-56$.

16. Sosnowski, M. R., Shtienberg, D., Creaser, M. L., Wicks, T. J., Lardner, R., and Scott, E. S. 2007. The influence of climate on foliar symptoms of Eutypa dieback in grapevines. Phytopathology 97:1284-1289.

17. Trouillas, F. P., and Gubler, W. D. 2004. Identification and characterization of Eutypa leptoplaca, a new pathogen of grapevine in Northern California. Mycol. Res. 108:1195-1204.

18. Trouillas, F. P., Úrbez-Torres, J. R., and Gubler, W. D. 2010. Diversity of diatrypaceous fungi associated with grapevine canker diseases in California. Mycologia.102:319-336.

19. Úrbez-Torres, J. R., Adams, P., Kama, J., and Gubler, W. D. 2009. Identification, incidence and pathogenicity of fungal species associated with grapevine dieback in Texas. Am. J. Enol. Vitic. 60: 497-507.

20. Úrbez-Torres, J. R., and Gubler, W. D. 2009. Pathogenicity of Botryosphaeriaceae species isolated from grapevine cankers in California. Plant Dis. 93:584-592.

21. Úrbez-Torres, J. R., Leavitt, G. M., Voegel, T. M., and Gubler, W. D. 2006. Identification and distribution of Botryosphaeria spp. associated with grapevine cankers in California. Plant Dis. 90:1490-1503. 